\title{
Keanekaragaman Tanaman Obat sebagai Larvasida dalam Upaya Pengendalian Vektor Demam Berdarah Dengue (DBD)
}

\author{
I Gede Wempi D.S. Permadi \\ Badan Litbang Kemenkes RI. Loka Litbang P2B2 Kemenkes Baturaja \\ Jl. Ahmad Yani Km 7 Kemelak Baturaja, 32111, Sumatera Selatan. Telp. +62.813.73746886. \\ e-mail: wempipermadi@yahoo.com
}

\begin{abstract}
Abstrak
Penyakit DBD yang diketahui disebabkan oleh nyamuk Aedes. Untuk mengurangi kasus penyakit degue adalah dengan pengendalian vektor baik secara kimia maupun secara hayati. Salah satu pengendalian penyebaran penyakit ini dilakukan dengan mengontrol vektornya yaitu nyamuk Aedes aegypti dengan menggunakan insektisida, misalnya Abate berbahan aktif Temephos. Bahan insektisida tersebut walaupun memiliki efektitas yang tinggi, akan tetapi bisa berdampak negatif terhadap lingkungan dan menimbulkan resistensi dari organisme target. Salah satu cara untuk memecahkan masalah tersebut adalah dengan penggunaan insektisida alami yang lebih ramah lingkungan atau dengan tumbuhan hayati. Metode penulisan yang digunakan dalam tulisan ini adalah pengambilan data melalui tinjauan pustaka. Analisis data secara diskriptif dan disajikan dalam bentuk gambar.
\end{abstract}

Kata Kunci : tanaman obat, larvasida

\section{Pendahuluan}

Penyakit DBD yang diketahui disebabkan oleh nyamuk Aedes, sangat umum ditemui di Indonesia. Lingkungan alam tropis, sanitasi buruk yang potensial sebagai sarang nyamuk, dan rendahnya kesadaran masyarakat menjadi alasan utama. Indonesia bahkan menempati posisi tertinggi dalam kasus penyakit dengue di Asia Tenggara dengan 10.000 kasus di tahun 2011. Untuk mengurangi kasus penyakit degue adalah dengan pengendalian vektor baik secara kimia maupun secara hayati. Salah satu pengendalian penyebaran penyakit ini dilakukan dengan mengontrol vektornya yaitu nyamuk Aedes aegypti dengan menggunakan insektisida, misalnya Abate berbahan aktif Temephos. Bahan insektisida tersebut walaupun memiliki efektitas yang tinggi, akan tetapi bisa berdampak negatif terhadap lingkungan dan menimbulkan resistensi dari organisme target. Salah satu cara untuk memecahkan masalah tersebut adalah dengan penggunaan insektisida alami yang lebih ramah lingkungan atau dengan tumbuhan hayati.

Indonesia terkenal kaya akan keanekaragaman hayati, termasuk jenis tumbuhan yang mengandung bahan aktif larvasida. Kandungan yang terdapat pada berbagai senyawa tumbuhan seperti tektoquinon, saponin, alkaloid dapat digunakan sebagai perstisida atau larvasida alami. 
Dalam tulisan ini, penulis ingin melakukan tinjauan pustaka tentang bermacam-macam larvasida hayati yang telah diteliti di Indonesia.

\section{Pembahasan}

Berbagai macam kandungan kimia tanaman obat yang dapat bermanfaat sebagai larvasida antara lain:

\section{Senyawa Alkaloid dan Tannon}

a. Daun Sirih (Piper betle Linn)

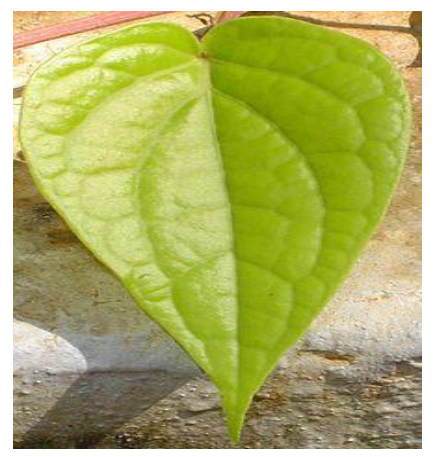

Gambar 1. Daun Sirih

Tanaman merambat ini bisa mencapai tinggi $15 \mathrm{~m}$. Batang sirih berwarna coklat kehijauan berbentuk bulat, beruas dan merupakan tempat keluarnya akar. Daunnya yang tunggal berbentuk jantung, berujung runcing, tumbuh berselang-seling, bertangkai, dan mengeluarkan bau yang sedap bila diremas. Panjangnya sekitar 5-8cm dan lebar 2-5cm. Bunganya majemuk berbentuk bulir dan terdapat daun pelindung $\pm 1 \mathrm{~mm}$ berbentuk bulat panjang. Pada bulir jantan panjangnya sekitar $1,5-3 \mathrm{~cm}$ dan terdapat dua benang sari yang pendek sedang pada bulir betina panjangnya sekitar $1,5-6 \mathrm{~cm}$ dimana terdapat kepala putik tiga sampai lima buah berwarna putih dan hijau kekuningan. Buahnya berbentuk bulat berwarna hijau keabu-abuan. Akarnya tunggang, bulat dan berwarna coklat kekuningan. Kandungan bahan aktif alkaloid, fenol dan kavikol daun sirih dapat dimanfaatkan sebagai pestisida nabati untuk mengendalikan hama penghisap. Menurut Adi Oka Wirnata LC50 pada konsentrasi 309,03ppm, sedangkan menurut menggunakan didapatkan LC50 pada konsentrasi 4.350ppm. Namun menurut penelitian Fahmi kefektifan daun sirih masih terdapat banyak kekurangan dibandikan temephos (abate@), yaitu air masih berwana, berbau dan berasa pahit.

b. Minyak biji Jarak Pagar (Jatropha curcas L., Euphorbiaceae)

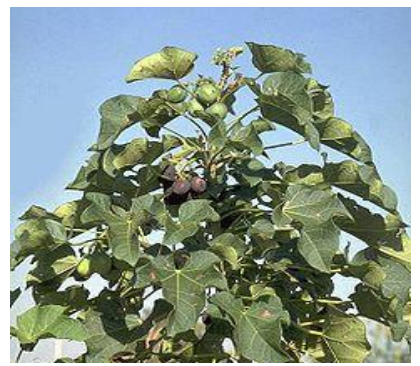

Gambar 2. Jarak Pagar Jarak pagar merupakan tumbuhan semak berkayu yang banyak ditemukan di daerah tropic. Tumbuhan ini dikenal dengan berbagai nama di Indonesia: jarak kosta, jarak budeg (Sunda); jarak gundul, jarak pager (Jawa); kalekhe paghar (Madura); jarak pager (Bali); lulu mau, paku kase, jarak pageh (Nusa Tenggara); kuman nema (Alor); jarak kosta, jarak wolanda, bindalo, bintalo, 
tondo utomene (Sulawesi); ai huwa kamala, balacai, kadoto (Maluku). LC100 pada konsentrasi 0,5\% (v/v) peneliti ciamis. LC50 pada konsentrasi 0,15\% (v/v)

\section{Etanol}

a. Daun Mimba (Azadirachta indica)

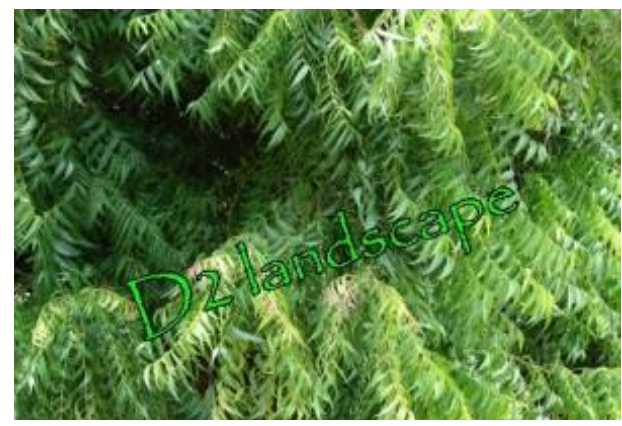

Gambar 3. Daun Mimba

Nama daerah/lokal : Mimba, Nimba (sunda), Intaran (Bali, Nusa Tenggara), Imbau (Jawa Timur), Mempheuh, Membha (Madura). Daun mimba adalah tumbuhan tergolong sub famili meliodeae, mimba ini berasal dari asia tenggara terutama di Indonesia di temukan di Nusa Tenggara Barat (NTB) dan Nusa Tenggara Timur (NTT). Ciri perawakan daun mimba adalah tinggi pohon mencapai 25m, pohon selalu hijau dan tidak menggugurkan daun, batang terlihat berbentuk lurus dan pendek, kulit batang yang tua berwarna abu-abu tua, tebal dan beralur. Daunnya panjang 6-8cm, lebar 1-3cm, daun majemuk dengan 7-17 pasang per tangkai, berbentuk lonjong dan bergigi, bunga berwarna putih dan krem . Daya larvasida daun mimba berasal dari kandungan aktifnya yang disebut azadirachtin dan salanin. Berdasar penelitian yang dilakukan oleh R.d.Ndione, O Faye, M Ndiaye, A Dieye, dan JM Afoutou menggunakan sediaan $1 \%$ sunneem pada tahun 2007, dengan menggunakan daun mimba terhadap larva Aedes aegypti Linnaeus 1762, yang juga mengandung azadirachtin, salalinin, meliantriol, nimbin dan nimbidin, mampu membunuh larva Aedes aegypti LC100 pada dosis $10 \mathrm{mg} / \mathrm{L}$ dan LC50 pada dosis $2 \mathrm{mg} / \mathrm{L}$. Penelitian lain yang dilakukan oleh Dyah (ugm) menggunakan fraksi minyak biji mimba didapatkan LC50 yaitu pada konsentrasi 3783,6ppm dan LC100 pada konsentrasi 1.2651,1ppm.

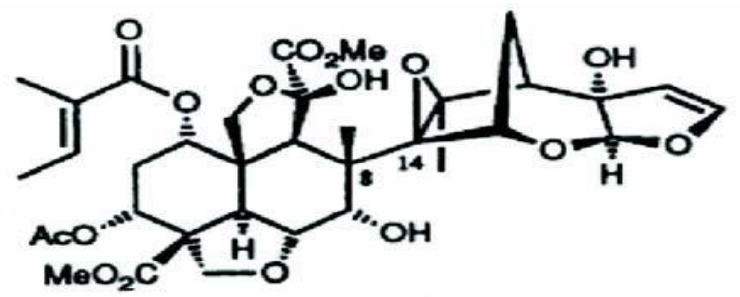

Gambar 4. Struktur Kimia Daun Mimba

b. Daun Dandang Gendis (Clinacanthus nutans L.)

Tanaman ini memiliki nama daerahdandang gendis (Jawa Tengah), ki tajam dan Ki Oray (Sunda). Dandang gendis merupakan tanamansemak belukar berbentuk perdu, batangnya 


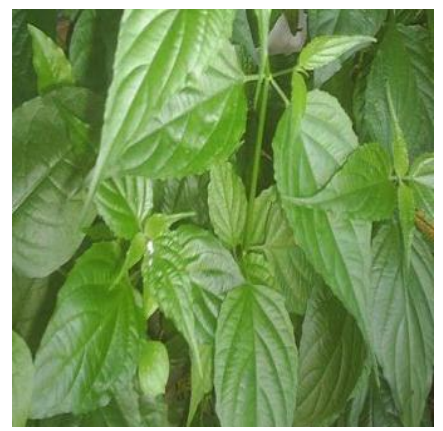

Gambar 5. Daun

Dandang Gendis

tegak dengan tinggi kurang lebih 2,5 m,beruas dan berwarna hijau. Daunnya berbentuk tunggal dan berhadapan satu samalain. Panjang daunnya berkisar antara 8-12 cm sedangkan lebar antara 4-6 cm. Daun tersebutberbentuk tulang menyirip dan berwarna hijau .Tanaman ini memiliki bungayang tumbuh di ketiak daun dan di ujung batang. Buahnya berwarna cokelat denganbentuk bulat memanjang. Berbiji kecil dan hitam. Akar tunggang berwarna putih kotor. Secara taksonomi dandang gendis diklasifikasikan dalam kingdom Plantae, divisi Spermatofita, kelas Dikotiledonae, ordo Solanales, famili Acanthaceae, genusClinacanthus, spesies Clinacanthus nutans Lindau.

\section{Minyak Basal dan miyak astiri}

a. Daun Selasih (Ocinum gratissimum L.)

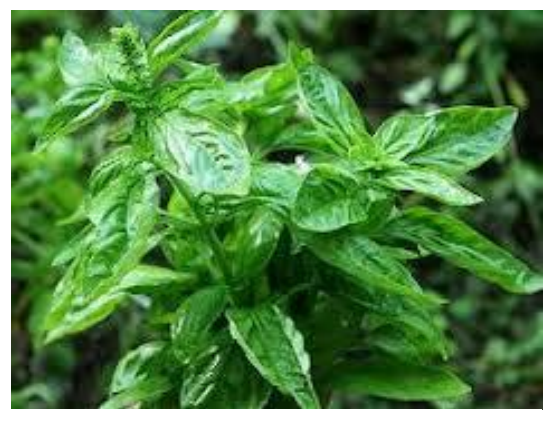

Gambar 6. Daun Selasih

Sebutan yang lazim digunakan untuk tanaman ini adalah selaseh, solasih, telasih, amping, kukuru juga sweet basil (Inggris). Merupakan tanaman rumput berupa terna yang tingginya dapat mencapai 1 meter. Tanaman famili Labiatae ini banyak terdapat di tepian jalan, sawah, tegalan atau hutan sampai ketinggian $500 \mathrm{~m}$ dpl. Kadangkadang dapat pula dijumpai pada daerah rendah hingga ketinggian $1.100 \mathrm{~m}$ dpl. Tanaman ini memiliki batang bersegi empat. Daunnya berbentuk bundar telur, panjangnya 2-2,5 cm, dengan tepi daun bergigi kasar atau kadang-kadang keriting. Daun ini mengeluarkan aroma harum bila diremas dan direndam dalam air. Bunganya terletak tegak pada ujung batang, tersusun dalam tandan, berukuran kecil dan berwarna putih. Dari bunga ini dihasilkan biji berwarna hitam, berukuran kecil dan akan mengembang seperti agar-agar bila direndam dalam air. Dalam tanaman selasih terkandung beberapa senyawa minyak atsiri seperti citral, linalool, dan metilchavicol yang dalam dunia perdagangan dikenal sebagai minyak basal atau basil oil. Dari penelitian yang dilakukan oleh Intitut pertanian Bogor di dapatkan LC50 yaitu pada konsentrasi 20,55\% (v/v)

\section{b. Rimpang Kunyit (Curcuma domestica Val)}

Nama lain dari kunyit

Indonesia : Kunyit, koneng (Sunda), kunir (Jawa)

Inggris : Curcuma, indian saffron, yellow ginger 


$\begin{array}{ll}\text { Melayu } & : \text { Kunyit } \\ \text { Vietnam } & : \text { Khuong hoang, nghe } \\ \text { Thailand } & : \text { Kha min } \\ \text { Pilipina } & : \text { Dilaw } \\ \text { Cina } & : \text { yu jin, jiang huang }\end{array}$

Kandungan dalam minyak astiri rimpang kunyit yaitu peladren, sabien, cineol, borneol, zingiberen, tirmeron, seskuiterpen alkohol. Menurut penelitian Marlinae, dkk. yaitu LC50 pada konsentrasi 7,79\%. Sedangkan menurut Panghiyangani, dkk. yaitu LC50 pada konsentrasi 0,4\% (v/v). Tinggi Tanaman Kunyit : 40-100 cm Batang Kunyit : Merupakan batang semu, tersusun dari pelepah daun dan agak lunak.Daun Kunyit : Berbentuk bulat telur memanjang. Bunga Kunyit : Muncul dari pucuk batang semu, panjang sekitar 10-15 $\mathrm{cm}$, berwarna putih. Rimpang Kunyit : Kulit luar berwarna jingga kecoklatan dan daging buah merah jingga kekuningan, tumbuh bercabang.

\section{UCAPAN TERIMA KASIH}

Terimakasih Penulis Ucapkan kepada Balai Besar Tawangmangu dan kolega yang tidak bisa disebutkan semuanya dalam tulisan ini. Rasa hormat tertinggi penulis sampaikan kepada Prof. Sudomo, yang telah member masukan berarti pada tulisan ini.

\section{DAFTAR PUSTAKA}

Notoatmodjo S. Metodologi Penelitian Kesehatan. PT. Rineka Cipta. Jakarta. 2005

Panghiyangani, R., Marlinae, L. dan Yuliana. Efek Ekstrak Rimpang Kunyit (Curcuma domestika val) sebagai larvasida Aedes aegypty vektor penyakit demam dengue dan demam berdarah dengue di kota Banjarbaru. Jurnal Buski vol 4 no 1 Juni 2012.

Marlinae, L., Lisda, H. dan Maya, V. Effectiveness of extract Rhizome Turmeric (Curcuma domestica Val) in Killing Aedes aegypty Larva Cause of Dengue Hemmorhagic Fever (DHF). Jurnal Kesehatan Lingkungan 2006; 3(2):22-28.

Parwata, O. A., Santi, S. R. dan Widhiartini, A. Aktifitas larvasida Minyak Astiri Daun SirihH (Piper betle Linn) terhadap larva Aedes aegypti. Journal of Chemistry Vol 5 No 1. 2011

Setyawati, D. Studi Pengaruh Ekstrak Daun Sirih (Piper bettle Linn) dalam Pelarut Aquades, Etanol dan Metanol terhdapa perkembangan larva nyamuk. Institut Pertanian Bogor. 2002. Skripsi

Risalina. Efek Larvasida Ekstrak Daun Sirih (Piper bettle, Linn) terhadap larva Aedes sp. Universitas Surakarta. Tesis. 2010 